\title{
THE MEDIATING ROLE OF NURSES' PROFESSIONAL COMMITMENT IN THE RELATIONSHIP BETWEEN CORE SELF-EVALUATION AND JOB SATISFACTION
}

IVANA BARAĆ ${ }^{1,2}$, NADA PRLIĆ ${ }^{2}$ JADRANKA PLUŽARIĆ ${ }^{2}$, NIKOLINA FARČIĆ ${ }^{2}$, and SUZANA KOVAČEVIĆ ${ }^{3}$

Josip Juraj Strossmayer University of Osijek, Osijek, Croatia

${ }^{1}$ Faculty of Medicine

${ }^{2}$ Faculty of Dental Medicine and Health, Nursing Department

${ }^{3}$ Faculty of Economics

\begin{abstract}
Objectives: The aim of this study has been to examine the degree to which it is possible to predict job satisfaction in hospital nurses based on core self-evaluation and the nurses' professional commitment. Psychological constructs of nurses' professional commitment could predict a level of job satisfaction. Material and Methods: A cross-sectional design was applied. Data was collected from 584 nurses of the University Hospital Osijek between April and November 2016. Core Self-Evaluation Scale (CSES), Job Satisfaction Survey (JSS) and Nurses ${ }^{6}$ Professional Commitment Scale (NPCS) were administrated to the study participants. Confirmatory factor analyses were conducted to test the validity of each questionnaire. Structural equation modeling was used for testing the prediction of nurses' professional commitment and core self-evaluation of job satisfaction. Nurses' professional commitment is variable, which functions as a mediator between predictor (core selfevaluation - CSE) and criterion variable (job satisfaction - JS). As a mediator, it explains what the effect is, provided that correlations among all variables are significant. Results: The correlation analyses reveal significant positive correlations between job satisfaction and core self-evaluation $(r=0.441, p>0.001)$ as well as between job satisfaction and nurses' professional commitment $(\mathrm{r}=0.464, \mathrm{p}>0.001)$. Furthermore, core self-evaluation significantly and positively correlates with nurses' professional commitment $(r=0.402, \mathrm{p}>0.001)$. The results have shown that nurses' professional commitment mediates the relationship between core self-evaluation and job satisfaction. The bootstrap analysis showed that core self-evaluation partially mediated the relationship between nurses' professional commitment and job satisfaction $(\beta=0.78$, $\left.\mathrm{p}<0.001^{* *}\right)$. The indirect effects of core self-evaluation on job satisfaction through nurses' professional commitment was also significant $\left(\beta=0.17, \mathrm{p}<0.001^{* *}\right)$. Conclusions: Nurses who are more committed to their work, regardless of the structure of personality, have greater satisfaction in their work. Int J Occup Med Environ Health 2018;31(5):649-658
\end{abstract}

Key words:

Job satisfaction, Nurses, Self-assessment, Mediation, Professional, Commitment

\section{INTRODUCTION}

There is a great number of studies on job satisfaction (JS) among nurses in the field of nursing management and organizational psychology. Through a systematic review of the literature, Lu et al. [1] have concluded that despite the varied levels of JS among nurses, the sources and consequences of job satisfaction were similar. Job satisfaction among hospital nurses is closely related to the working conditions, organizational environment, job stress, role

Received: August 23, 2017. Accepted: December 18, 2017.

Corresponding author: Ivana Barać, Josip Juraj Strossmayer University of Osijek, Faculty of Dental Medicine and Health, Nursing Department, Crkvena 21, HR-31000, Osijek, Croatia (e-mail: ivana.barac@mefos.hr). 
conflict and ambiguity, and organizational and professional commitment [1].

In addition to organizational factors, recent studies focus on research of the psychological constructs of JS. Studies show that personal psychological constructs, including core self-evaluation (CSE) and attitudes of commitment to work, could significantly predict a person's level of JS [2]. The most well-known theory of CSE precisely explores the relation between internal psychological conditions and JS and it has been shown that there is a significant relation between these two theories. The nurses' professional commitment (NPC) has also proven to be an important psychological construct in the work of nurses. The nursing profession includes a strong personal commitment to duties, the society and the community, as well as a belief in respect and value of each individual [3]. According to our analysis, no study has examined the mediator effect of NPC on the relationship between CSE and JS. Therefore, the aim of this study is to examine whether NPC, a personalitybased construct, mediates the association between CSE and JS among hospital nurses. Furthermore, it is also examined whether there is an indirect relation between CSE and JS through NPC.

\section{Nurses' job satisfaction and core self-evaluation}

Job satisfaction has been defined as the extent to which people like their jobs and their various aspects [4]. Hayes et al. [5] list a number of factors that contribute to explaining nurses' JS which they have classified as intrapersonal, inter-personal or extra-personal factors. Intrapersonal factors include the characteristics of nurses, such as their education and individual coping strategies. Inter-personal factors relate to professional relationships and interactions among nurses, other health professionals who provide direct care and patients. Factors related to the attitudes of nurses toward the institution in terms of governmental policies, pay, and organization are extra-personal factors [5]. Judge et al. state that the internal job characteristics include the attributes associated with the job itself, such as the importance of the work, its complexity, and positive task feedback [6].

A person with a positive CSE has a better estimate of the characteristics of the job, as well as a sooner return from sick leave, which ultimately affect JS. Core self-evaluation represents the fundamental appraisals individuals make about their self-worth and capabilities. It represents stable personality traits, including an individuals' subconscious and fundamental evaluation of themselves, one's own abilities and self-control [7]. The concept of CSE involves four personality traits: (i) locus of control, the perception that outcomes are contingent upon either personal behavior or external forces; (ii) neuroticism, a tendency to express negative emotionality; (iii) generalized self-efficacy, an appraisal of one's ability to perform across situations; and (iv) self-esteem, an individual's sense of self-worth [7].

Core self-evaluation shows a strong relationship with JS [8,9], effective nursing work environments [10], work success [11], nurses' job stress [12] and turnover intentions [13]. One of dimension of CSE, neuroticism, proved to be the most significantly related with JS [14]. Apart from the connection of CSE and JS, many studies have shown possible mediators that may explain why CSE is associated with dimensions of JS and job outcomes. Mediators include job stress [15], goal setting, motivation and performance [16], work-family conflict [17], nurses' job burnout [18], perceived job characteristics and job complexity [19]. Core self-evaluation theory, as well as its correlation with and contribution to NPC and JS, should be tested with hospital nurses.

\section{Nurses' professional commitment}

Professional commitment involves believing in and accepting professional goals and values, tendency to make significant efforts in the job, membership in professional 
bodies, having a sense of pride in one's career [20,21] and striving for professional activities [20]. It is an important construct because it contributes to our understanding of how people develop, make sense of and integrate their multiple work-related commitments [22]. In nursing, professional commitment is defined as the intention to stay and work as a nurse [20,23-25] feeling responsibility toward the profession, being involved in the profession [26] and a tendency to enhance career promotion. Professional commitment is an important variable in the discussion about JS since it has been found that strong commitment to a profession is associated with JS and the intention to remain in the profession [27]. In the context of nursing, this means that the more committed the nurses are, the more likely it is that they will stay devoted to the profession and the organization. Nurses without a sense of professional commitment, find it difficult to continue to serve adequately as professionals, and it may have a negative impact on the quality of care [28]. Adding to existing literature, the aim of this study is to examine whether NPC contributes as a possible mediator to the relationship between CSE and JS among hospital nurses.

\section{MATERIAL AND METHODS}

\section{Procedure and participants}

This study was conducted on a sample of 584 nurses who worked at the Osijek University Hospital in Croatia, in the hospital wards, operating rooms, intensive care unit (ICU) or outpatient clinics, during an eight-month period of April-November 2016. The response rate was 59\% and the participants were selected using the principle of availability. The study does not include respondents who were absent for a long period of time during data collection, due to either vacation or illness. In this study, 532 (91.1\%) participants were female and $52(8.9 \%)$ were male. The mean age of the participants was 39.2 years old (standard deviation $(\mathrm{SD})=9.6$ years $)$ and the mean of their work experience was 19 years $(\mathrm{SD}=9.7$ years). In the sample, 424 nurses $(72.6 \%)$ had vocational diplomas, 145 (24.8\%) had Bachelor's degrees, and 15 (2.6\%) had Master's degrees. Moreover, 404 nurses (69.2\%) had rotating shifts and 132 nurses $(22.6 \%)$ worked only morning shifts. The remaining $47(8 \%)$ worked the daily shifts (morning and afternoon).

To test for possible mediating effects of professional commitment, we performed regression-based mediation analyses. Their approach tests for mediation by assessing the statistical significance of the indirect effect, i.e., the path from the independent variable (CSE) via the mediator variable (NPC) to the dependent variable (JS). Bootstrapping methods to estimate the confidence intervals (CI) for the indirect effects of interest in mediation have been shown to be superior in simulated data sets in comparison to a reliance on the Sobel test.

\section{Ethical consideration}

The relevant ethics committee of the University Hospital Osijek approved this research. All of the subjects were informed in writing about the research's aim, and signed an informed consent to participate in the research. The subjects' anonymity, both during and after the research, was guaranteed.

\section{Measures}

\section{Core Self-Evaluation Scale (CSES)}

The Core Self-Evaluation Scale is a 12-item questionnaire developed by Judge and Bono to operationalize the construct of CSE [9]. It has been designed to measure four traits that compose this construct (self-esteem, generalized self-efficacy, locus of control, and neuroticism). Items are rated on a scale ranging from 1 (strongly disagree) to 5 (strongly agree). Relevant items are reverse-coded. The scale scores are the sum of the ratings of the items with the total score of 12-60. Cronbach's $\alpha$ for the subscales ranged between $0.71-0.82$. 


\section{Job Satisfaction Survey (JSS)}

The original JSS assesses nine dimensions, namely pay, promotion, fringe benefits, contingent rewards, supervision, co-workers, operating conditions, nature of work, and communication. Psychometric validity has been done for the nursing population in the Republic of Croatia. The seven-factor structure of the measure was confirmed and the overall JS score was computed by summing all 34 items. Items were rated on a scale ranging from 1 (strongly disagree) to 6 (strongly agree). Negatively worded items were reversed. Scores based on the sum of all 34 items may range between 34-204 [29]. Cronbach's $\alpha$ for the subscales ranged between $0.61-0.78$.

Nurses' Professional Commitment Scale (NPCS)

Nurses' Professional Commitment Scale is a 26-item questionnaire designed by Lin et al. [30] to operationalize the construct of professional commitment in nursing. It assesses three dimensions: nursing professional compliance, involvement of nursing professionals and retention of nursing professionalism. Items were rated on a scale ranging from 1 (strongly disagree) to 5 (strongly agree). The total score ranged between 26-130. Cronbach's $\alpha$ for the subscales ranged between $0.93-0.95$.

\section{RESULTS}

\section{Validity of scales (questionnaires)}

Exploratory and confirmatory factor analyses were conducted via SPSS and AMOS software was used for testing the psychometric validity of each questionnaire.

\section{Job satisfaction scale}

Before conducting the confirmatory factor analysis for the JSS, the multivariate normality of the data had to be examined [31]. The Kolmogorov-Smirnov test is not significant $(0.065, \mathrm{p}>0.05)$, which indicates a normal distribution. The skewness $(0.060)$ and kurtosis $(-0.165)$ were within the normal distribution [32]. The test-retest coefficient for the whole survey was $r=0.826^{* *}, p<0.000$ and was tested on 48 participants. To test whether the data of the JSS lends itself to the factor analysis, Bartlett's test of Sphericity and Kaiser-Meyer-Olkin (KMO) sample sufficiency tests were conducted. The results of Bartlett's test of Sphericity were significant $\left(\mathrm{Chi}^{2}=5016.5, \mathrm{p}<0.00\right)$, supporting the assumption that there was a high correlation among items in the correlation matrix [33]. The KMO test result was 0.78 . The results of the exploratory factor analysis explained overall cumulative variance of $48.4 \%$ for the 7 factors. The confirmatory factor analysis was performed; the common indices for the 7 factors indicate a generally adequate fit of the 7-factor model: relative $\mathrm{Chi}^{2} / \mathrm{df}=2.8$, comparative fit indices $(\mathrm{CFI})=0.83$, Tucker-Lewis index (TLI) $=0.85$, and root mean square error of approximation $($ RMSEA $)=0.05$. Cronbach's $\alpha$ was 0.83 .

\section{Core Self-Evaluation Scale}

Following the procedure described above, the factor validity was supported: overall Cronbach's $\alpha$ was 0.74 . Bartlett $\mathrm{Chi}^{2}=1920.797$, two-tailed $\mathrm{p}<0.01$, and KMO was 0.76. Overall cumulative variance explained was $65.5 \%$ for the 4 factors. The common indices for the 4 factors indicate a generally adequate fit: $\mathrm{GFI}=0.829$, $\mathrm{CFI}=0.66$ and $\mathrm{TLI}=0.53$, RMSEA $=0.150$.

\section{Nurses' Professional Commitment Scale}

Following the procedures described above, the factor validity was supported: overall Cronbach's $\alpha$ was 0.95 , the overall cumulative variance explained was $64.3 \%$, $\mathrm{KMO}=0.94$, Bartlett's $\mathrm{Chi}^{2}=10303.9$, two-tailed $p<0.01$. The eigenvalues for the 3 factors described above were $11.7,2$, and 1.2 , respectively. The common indices for the 3 factors indicate a generally adequate fit: $\mathrm{GFI}=0.80, \mathrm{CFI}=0.82$ and TLI $=0.799$; and RM$\mathrm{SEA}=0.118$. According to these analyses, the questionnaires-based results of this research are valid. 


\section{Descriptive statistics and correlation analysis}

Descriptive statistics, bivariate correlations and Cronbach's $\alpha$ for all the variables are presented in the Table 1 .

The correlation analyses reveal significant positive correlations between JS and CSE as well as between JS and NPC. Furthermore, CSE significantly and positively correlates with NPC.

\section{Regression analysis}

As shown in the Table 2, in step 1, gender, age, and work experience were not found to affect JS. In step 2, CSE was positively associated with JS $(\beta=0.443, p<0.01)$. In step 3, where NPC was added $(\beta=0.341, \mathrm{p}<0.01)$, the regression coefficient for CSE in relation to JS score was reduced from 0.443 to $0.303(\mathrm{p}<0.01)$.

\section{Mediation and structural model}

Since we have hypothesized that there are causal sequences among variables [34], the structural equation model (SEM) was used for analyzing the mediation effect. First of all, the direct effect of CSE on JS was tested without the mediator. The directly standardized path from CSE to JS was significant $\left(\beta=2.70, p<0.001^{* *}\right)$. Then, a partiallymediated model containing mediator (NPC) and direct paths

Table 1. Descriptive statistics and bivariate correlations of job satisfaction (JS), nurses' professional commitment (NPC), core self-evaluation (CSE) among studied nurses ( $\mathrm{N}=584)$, Croatia

\begin{tabular}{lccc}
\hline & Variable & \multicolumn{3}{c}{ Correlations } \\
\cline { 2 - 4 } & JS & NPC & CSE \\
\hline JS & & $0.464^{* * *}$ & $0.441^{* *}$ \\
NPC & & & $0.402^{* *}$ \\
M \pm SD & $111.5 \pm 17.3$ & $93.2 \pm 15.9$ & $40.5 \pm 5.4$ \\
Cronbach's $\alpha$ & 0.830 & 0.950 & 0.740 \\
\hline
\end{tabular}

$\mathrm{M}$ - mean; SD - standard deviation.

$* \mathrm{p}<0.05 ; * \mathrm{p}<0.01$.

Table 2. Hierarchical regression analysis predicting job satisfaction (JS) accounted by core self-evaluation (CSE) and nurses' professional commitment (NPC) among studied nurses $(\mathrm{N}=584)$, Croatia

\begin{tabular}{lccc}
\hline & \multicolumn{3}{c}{ Dependent JS } \\
& Independent variable & $(\beta)$ & step 3 \\
\cline { 2 - 4 } & step 1 & step 2 & -0.026 \\
\hline Gender & -0.040 & -0.008 & -0.060 \\
Age & -0.110 & -0.068 & 0.072 \\
$\quad$ Seniority [years] & 0.091 & 0.076 & $0.303^{* *}$ \\
CSE & & $0.443^{* *}$ & $0.341^{* *}$ \\
NPC & & & 0.288 \\
Adjusted $\mathrm{R}^{2}$ & -0.002 & 0.192 & \\
\hline
\end{tabular}

$\beta$-standardized regression coefficient.

${ }^{*} \mathrm{p}<0.05 ;{ }^{* *} \mathrm{p}<0.01$ (two-tailed). 
from CSE to JS was tested. The examination of the parameter estimates show that the standardized path coefficients from CSE to JS, from CSE to NPC, and from NPC to JS were all significant (Table 3 ).

The mediating effect of NPC between CSE and JS was estimated using the bootstrap estimation procedure (for a sample of 1500). This method is used when the indirect effect estimates, which are the products of direct effects, do not follow the normal distribution. Such a statistical situation suggests that the bootstrap method yields the most accurate confidence intervals for indirect effects $[35,36]$.

The Table 4 shows the indirect effects and their associated $95 \%$ confidence interval. As shown in the Table 4, CSE has significant direct effect on JS. In addition, the indirect effects of CSE on JS through NPC are also significant (empirical 95\% CI confidence interval does not overlap with 0 ).

\section{DISCUSSION}

Job satisfaction among nurses is an important topic of research. Nevertheless, it is necessary to continually examine it because of the many factors that contribute to JS. The primary purpose of this research was to examine whether professional commitment, a specific construct in the nursing field, could act as a mediator in the relationship between CSE and JS. No research has yet analyzed the relationship and connection between these constructions, with nurses' participation.

Our hypothesis was that CSE was associated with professional commitment, which in turn was associated with aspects of JS. First, the results showed that there was a significant relationship between CSE and JS. One of the constructs of personality that has received a great deal of attention lately, especially in organization psychology, is CSE

Table 3. Direct effect of unstandardized estimates in partially-mediated model containing mediator nurses' professional commitment (NPC) and direct paths from core self-evaluation (CSE) to job satisfaction (JS) among studied nurses $(\mathrm{N}=584)$, Croatia

\begin{tabular}{lcccc}
\hline \multicolumn{1}{c}{ Model pathway } & $\beta$ & SE & CR & p \\
\hline CSE $\rightarrow$ NPC & 3.45 & 0.254 & 13.6 & $0.001^{* *}$ \\
CSE $\rightarrow$ JS & 0.78 & 0.168 & 4.6 & $0.001^{* *}$ \\
NPC $\rightarrow$ JS & 0.17 & 0.029 & 5.8 & $0.001^{* *}$ \\
\hline
\end{tabular}

$\beta$ - standardized regression coefficient; SE - standard error; CR - critical ration.

** $\mathrm{p}<0.001$ (two-tailed).

Table 4. Direct and indirect effects of core self-evaluation (CSE) on job satisfaction (JS) through nurses' professional commitment (NPC) among studied nurses $(\mathrm{N}=584)$, Croatia

\begin{tabular}{lcc}
\hline \multicolumn{1}{c}{ Model pathway } & Estimated effect & $95 \%$ CI \\
\hline Direct effect & & \\
$\mathrm{CSE} \rightarrow \mathrm{NPC}$ & $0.611^{\#}$ & $0.527-0.685$ \\
$\mathrm{CSE} \rightarrow \mathrm{JS}$ & $0.323^{\#}$ & $0.167-0.473$ \\
$\mathrm{NPC} \rightarrow \mathrm{JS}$ & $0.391^{\#}$ & $0.199-0.608$ \\
Indirect effect & & \\
$\mathrm{CSE} \rightarrow \mathrm{NPC} \rightarrow \mathrm{JS}$ & $0.239^{\#}$ & $0.114-0.382$ \\
\hline
\end{tabular}

$\mathrm{CI}$ - confidence interval.

\# Empirical 95\% CI does not overlap with 0. 
which includes fundamental assessment of the competence and capabilities [37] and respectively provides clear support for research on personality traits that contribute to and form the basis of the affective assessment of work.

We decided for CSE theory because it was proven that a wide range of professional and organizational behavior may be understood by using it. In this study, CSE has a beneficial impact and is related in the expected direction to JS, which is consistent with previous studies $[9,38]$. There is a significant direct effect of CSE on JS, before we turn the mediator variable. After we add the mediator variable (NPC), the effect of CSE on JS decreases but remains significant. We have thus obtained partial mediation. It has been proven that CSE has been attributed to several professional dimensions, such as professional compliance and involvement. Specifically, it seems that the presence of higher self-esteem and self-efficacy with higher external locus of control and lower neuroticism make nurses' more stable, more secure in professional compliance, and more confident about their involvement in the nursing profession. These characteristics seem to help the individual to develop better professional values, and in turn, have a beneficial impact on the level of the individual's JS. In other words, a person with a positive CSE will assess positive professional features [6].

In this study, NPC explains almost $34 \%$ of the variance of JS. We have thus discovered that the NPC mediates between CSE and JS, that is, in addition to the dimensions of the personality traits, definitely contributes to nurses' JS. On the other hand, job dissatisfaction has proven to affect various significant areas such as life-being [39], career success [40], impact on delivering healthcare to the patients [41], nurses' job turnover [42]. This indicates that NPC is one of the direct predictors of mentioned areas of life and work. It may be estimated that the more committed to their profession nurses are, the more likely they are to remain committed to the organization and the less are they intent on leaving the nursing profession [43].
Quality healthcare and professionalism were also the most important variables that influence hospitals' organizational climates and nurses have reported that they would stay at their jobs even if these jobs did not meet their expectations [44].

This research may clearly imply that a professional commitment must be able to be developed with nurses in order to achieve a greater degree of job satisfaction. This research should be significant for everyone involved in the management of hospitals and departments, especially nurse managers. It is necessary to develop programs in permanent professional training such as supervising work in hospital departments and workshops on professional self-empowerment. This research is evidenced by intervention to evaluate new or existing practices. It generates new knowledge and its findings have implications for units or institutions. Those with higher CSE scores will always have higher professional efficacy and self-esteem [45], which may result in higher nursing compliance, involvement in and retention of nursing professionalism.

\section{CONCLUSIONS}

Nurses' Professional Commitment Scale mediates between CSE and JS and positively contributes to JS with nurses. This study adds to the body of knowledge around NPC and the opportunity to improve the lives of nurses with strategies to increase professional commitment. Nurses' Professional Commitment Scale should be included in psychosocial causal models that link CSE and JS, which indicates the need for activities in vocational training interventions designed to impact levels of low professional commitment in the attitude of nurses.

\section{Limitation}

The results of this research refer to the institution where the research was conducted. Although it implies the importance of the NPC, it is necessary to do so for each institution and see which NPC areas need to be developed. 
Although the use of logical mediation implies a causal chain that flows from a predictor variable (CSE) to a mediator variable (NPC) to an outcome variable (JS), such propositions cannot be rigorously evaluated on the basis of the cross-sectional data available for this study. Longitudinal data would help address these important causal issues.

\section{ACKNOWLEDGMENTS}

I am grateful to all hospital nurses in the University Hospital Osijek for their support and contribution in data collection.

\section{REFERENCES}

1. Lu H, Barriball KL, Zhang X, While AE. Job satisfaction among hospital nurses revisited: A systematic review. Int J Nurs Stud. 2012;49(8):1017-38, https://doi.org/10.1016/ j.ijnurstu.2011.11.009.

2. Bowling N, Hendricks E, Wagner S. Positive and negative affectivity and facet satisfaction: A meta-analysis. J Bus Psychol. 2008;23(3):115-25, https://doi.org/10.1007/s10869-008-9082-0.

3. Kozier B, Erb GL, Blais K. Professional nursing practice: Concepts and perspectives. 3rd ed. California: Addison-Wesley; 1997.

4. Spector PE. Job Satisfaction: Application, Assessment, Causes, and Consequences. United Kingdom: Sage Publications; 1997.

5. Hayes B, Bonner A, Pryor J. Factors contributing to nurse job satisfaction in the acute hospital setting: a review of recent literature. J Nurs Manag. 2010;18(7):804-14, https://doi. org/10.1111/j.1365-2834.2010.01131.x.

6. Judge TA, Bono JE, Erez A, Locke EA. Core self-evaluations and job and life satisfaction: The role of self-concordance and goal attainment. J Appl Psychol. 2005;90(2):257-68, https:// doi.org/10.1037/0021-9010.90.2.257.

7. Chang CH, Lance Ferris D, Johnson RE, Rosen CC, Tan JA. Core self-evaluations: A review and evaluation of the literature. J Manage. 2012;38(1):81-128, https://doi.org/ $10.1177 / 0149206311419661$.
8. Bono JE, Judge TA. Core self-evaluations: A review of the trait and its role in job satisfaction and job performance. Eur J Pers. 2003;17:5-18, https://doi.org/10.1002/per.481.

9. Judge TA, Bono JE. Relationship of core self-evaluations traits - selfesteem, generalized self-efficacy, locus of control, and emotional stability - with job satisfaction and job performance: A meta-analysis. J Appl Psychol. 2001;86(1):80-92, https://doi.org/10.1037/0021-9010.86.1.80.

10. Laschinger HKS, Nosko A, Wilk P, Finegan J. Effects of unit empowerment and perceived support for professional nursing practice on unit effectiveness and individual nurse well-being: A time-lagged study. Int J Nurs Stud. 2014;51(12):1615-23, https://doi.org/10.1016/j.jjnurstu.2014. 04.010 .

11. Judge TA, Hurst C. Capitalizing on one's advantages: Role of core self evaluations. J Appl Psychol. 2007;92:1212-27, https://doi.org/10.1037/0021-9010.92.5.1212.

12. Almost J, Doran DM, Mcgillis Hall L, Spence Laschinger HK. Antecedents and consequences of intra-group conflict among nurses. J Nurs Manag. 2010;18(8):981-92, https://doi.org/10.1111/j.1365-2834.2010.01154.x.

13. Harris KJ, Harvey P, Kacmar KM. Do social stressors impact everyone equally? An examination of the moderating impact of core-self evaluations. J Bus Psychol. 2009;24(2):153-64, https://doi.org/10.1007/s10869-009-9096-2.

14. Mróz J, Kaleta K. Relationships between personality, emotional labor, work engagement and job satisfaction in service professions. Int J Occup Med Environ Health. 2016;29(5): 767-82, https://doi.org/10.13075/ijomeh.1896.00578.

15. Brunborg GS. Core self-evaluations: A predictor variable for job stress. Eur Psychol. 2008;13(2):96-102, https://doi. org/10.1027/1016-9040.13.2.96.

16. Erez A, Judge TA. Relationship of core self-evaluations to goal setting, motivation, and performance. J Appl Psychol. 2001;86(6):1270-9, https://doi.org/10.1037/0021-9010.86. 6.1270 .

17. Boyar SL, Mosley DC, Jr. The relationship between core selfevaluations and work and family satisfaction: The mediating 
role of work-family conflict and facilitation. J Vocat Behav. 2007;71(2):265-81, https://doi.org/10.1016/j.jvb.2007.06.001.

18. Zhou Y, Lu J, Liu X, Zhang P, Chen W. Effects of Core Self-Evaluations on the Job Burnout of Nurses. The Mediator of Organizational Commitment. PLoS ONE. 2014;9(4): e959975, https://doi.org/10.1371/journal.pone.0095975.

19. Judge TA, Bono JE, Locke EA. Personality and job satisfaction: The mediating role of job characteristics. J Appl Psychol. 2000;85(2):237-49, https://doi.org/10.1037/0021-9010.85.2.237.

20. Teng CI, Lotus Shyu YI, Chang HY. Moderating effects of professional commitment on hospital nurses in Taiwan. J Prof Nurs. 2007;23(1):47-54, https://doi.org/10.1016/j.profnurs.2006.10.002.

21. Drey N, Gould D, Allan T. The relationship between continuing professional education and commitment to nursing. Nurse Educ Today. 2009;29(7):740-5, https://doi.org/10.1016/ j.nedt.2009.03.008.

22. Lee K, Carswell JJ, Allen NJ. A meta-analytic review of occupational commitment: Relations with person-and workrelated variables. J Appl Psychol. 2000;85:799-811, https:// doi.org/10.1037/0021-9010.85.5.799.

23. Gould D, Fontenla M. Commitment to nursing: Results of a qualitative interview study. J Nurs Manag. 2006;14(3): 213-21, https://doi.org/10.1111/j.1365-2934.2006.00577.x.

24. Parry J. Intention to leave the profession: Antecedents and role in nurse turnover. J Adv Nurs. 2008;64(2):157-67, https://doi.org/10.1111/j.1365-2648.2008.04771.x.

25. Flinkman M, Laine M, Leino-Kilpi H, Hasselhorn HM, Salanterä S. Explaining young registered Finnish nurses' intention to leave the profession: A questionnaire survey. Int J Nurs Stud. 2008;45(5):727-39, https://doi.org/10.1016/ j.jinurstu.2006.12.006.

26. Yang HH, Huang FF, Lai YH, Hsieh CJ, Liao YS, Chao WC, et al. Perceived organizational culture, professional commitment, advice network and job satisfaction of novice nurses. WSEAS Trans Commun. 2010;9(9):595-604.

27. Wolf ZR, Hoerst B. Professional commitment in RNBSN and basic BSN students: Program evaluation. Nurse
Educ. 2007;32(2):61-5, https://doi.org/10.1097/01.nne.0000 264329.63662.1b.

28. Hayhurst A, Saylor C, Stuenkel D. Work environmental factors and retention of nurses. J Nurs Care Qual. 2005;20(3):283-8, https://doi.org/10.1097/00001786-2005070 00-00015.

29. Barać I, Prlić N, Lovrić R, Kanisek S, Dubac Nemet L, Plužarić J. Development and psychometric testing of the Croatian version of the Job Satisfaction Scale in hospital nurses. J Nurs Meas. 2018;26(1).

30. Li CJ, Wang HC, Li TC, Huang LC. Reliability and Validity of Nurses' Job Satisfaction Scale and Nurses' Professional Commitment. Mid Taiwan J Med. 2007;12(2):65-75.

31. Kline RB. Principles and Practice of Structural Equation Modeling. New York, London: The Guilford Press; 2010.

32. Pett MA, Lackey NR, Sullivan JJ. Making Sense of Factor Analysis: The use of factor analysis for instrument development in health care research. California: Sage Publications; 2003.

33. Byrne BM. Structural equation modeling with AMOS: Basic concepts, applications and programming. New York: Routledge: Taylor and Francis Group; 2010.

34. Tabachnick BG, Fidell LS. Using multivariate statistics. Boston: Allyn \& Bacon; 2007.

35. Preacher KJ, Hayes AF. SPSS and SAS procedures for estimating indirect effects in simple mediation models. Behav Res Methods Instrum Comput. 2004;36(4):717-31, https:// doi.org/10.3758/bf03206553.

36. MacKinnon DP, Lockwood CM, Williams J. Confidence limits for the indirect effect: Distribution of the product and resampling methods. Multivariate Behav Res. 2004;39 (1):99-128, https://doi.org/10.1207/s15327906mbr3901_4.

37. Judge TA, Locke EA, Durham CC, Kluger AN. Dispositional effects on job and life satisfaction: The role of core evaluations. J Appl Psychol. 1998;83(1):17-34, https://doi.org/ 10.1037/0021-9010.83.1.17.

38. Dormann C, Fay D, Zapf D, Frese M. A state-trait analysis of job satisfaction: On the effect of core self-evaluations. 
Appl Psychol. 2006;55(1):27-51, https://doi.org/10.1111/ j.1464-0597.2006.00227.x.

39. Rode JC. Job satisfaction and life satisfaction revisited: A longitudinal test of an integrated model. Hum Relat. 2004;57(9):1205-30, https://doi.org/10.1177/001872 6704047143.

40. Judge TA, Cable DM, Boudreau JW, Bretz RD. An empirical investigation of the predictors of executive career success. Pers Psychol. 1995;48(3):485-519, https://doi. org/10.1111/j.1744-6570.1995.tb01767.x.

41. Brooks I, Swailes S. Analysis of relationship between nurse influences over flexible working and commitment to nursing. J Advan Nurs. 2002;38(2):117-26, https://doi.org/10.1046/ j.1365-2648.2002.02155.x.
42. Lu KY, Pan SM, Lee LL, Shia LY, Chang YY. The influence of professional commitment on turnover intention. Kaohsiung J Med Sci. 2001;17(7):364-71.

43. Chang CS, Du PL, Huang IC. Nurses' perception of severe acute respiratory syndrome: Relationship between commitment and intention to leave nursing. J Adv Nurs. 2006;54(2):171-9.

44. Mrayyan MT. Hospital organizational climates and nurses' intent to stay: Differences between units and wards. Contemp Nurse. 2008;27(2):223-36, https://doi.org/10.5172/co nu.2008.27.2.223.

45. Li X, Guan L, Chang H, Zhang B. Core self-evaluation and burnout among Nurses: the mediating role of coping styles. PLoS One. 2014;9(12):e115799, https://doi.org/10.1371/journal.pone.0115799.

This work is available in Open Access model and licensed under a Creative Commons Attribution-NonCommercial 3.0 Poland License - http://creativecommons.org/ licenses/by-nc/3.0/pl/deed.en. 